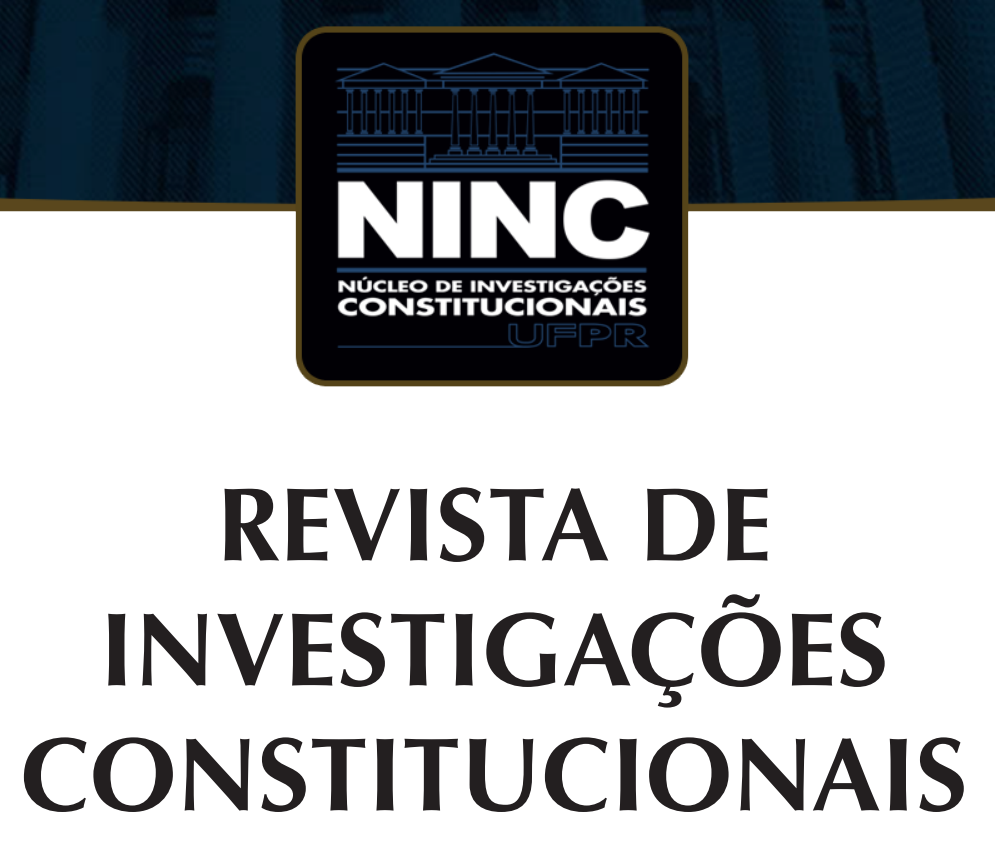

JOURNAL OF CONSTITUTIONAL RESEARCH

vol. 6 | n. 1 | janeiro/abril 2019 | ISSN 2359-5639 | Periodicidade quadrimestral Curitiba | Núcleo de Investigações Constitucionais da UFPR | www.ninc.com.br 


\section{A Revista de Investigações Constitucionais é indexada no SciELO}

\section{The Journal of Constitutional Research is covered in SciELO}

Um dos maiores desafios dos editores de periódicos científicos é atender às rigorosas exigências das principais bases de dados, diretórios e fontes de informação. Além da preocupação com qualidade das pesquisas submetidas à apreciação do Conselho Editorial e do Conselho de Pareceristas, com o enquadramento na linha editorial da revista, com a diversidade geográfica dos autores, entre outras, a indexação do periódico nesses repositórios é fundamental para ampliar a sua visibilidade, a leitura e o acesso aos artigos publicados, bem como permitir, em alguns casos, a aferição do impacto da revista.

No seu quinto ano de existência, a Revista de Investigações Constitucionais logrou cumprir os rígidos requisitos estabelecidos pelo SciELO - Scientific Electronic Library Online e recebeu a carta de aceitação para indexação. Atualmente, o periódico já se encontra indexado, com todo o seu conteúdo disponível no sítio eletrônico do SciELO. Essa biblioteca digital de livre acesso é hoje um dos principais portais da América Latina voltados à divulgação e disseminação da produção científica em formato eletrônico e de acesso aberto. A rede conta com a participação de países como África do Sul, Argentina, Bolívia, Brasil, Chile, Colômbia, Costa Rica, Cuba, Espanha, México, Peru, Portugal, Uruguai e Venezuela.

É com muita alegria e gratidão aos autores, membros do Corpo Editorial, pareceristas e autores que comunicamos a notícia dessa importante conquista ao nosso

Como citar este editorial | How to cite this editorial: HACHEM, Daniel Wunder. A Revista de Investigações Constitucionais é indexada no SciELO. Revista de Investigações Constitucionais, Curitiba, vol. 6, n. 1, p. 7-9, jan./abr. 2019. DOI: 10.5380/rinc.v6i1.69178 
público-leitor, com a expectativa de que essa indexação amplie ainda mais o acesso às publicações de alto nível de excelência que compõem os números da revista.

Neste número, o primeiro do ano de 2019, publicamos artigos em 3 idiomas (inglês, espanhol e português), de autores vinculados a 11 instituições de ensino superior de 4 países diferentes: Chile, Cuba, Estados Unidos e de 5 diferentes unidades federativas da República Federativa do Brasil, com representação das regiões Sul, Sudeste e Nordeste: Rio Grande do Sul, Santa Catarina, Rio de Janeiro, São Paulo e Ceará. Dos trabalhos publicados, 87,5\% são de Professores Doutores, 25\% redigidos em língua estrangeira, 37,5\% dos artigos possuem entre seus autores pesquisadores afiliados a instituições estrangeiras e 100\% dos autores são exógenos ao Estado do Paraná. São eles:

- Brazil in comparative perspective: the legacy of the founding, and the future of constitutional development

\section{Ana Beatriz Vanzoff Robalinho Cavalcanti}

Master of Laws (LL.M) at Yale Law School (New Haven, United States)

- La iniciativa legislativa popular en América Latina - Un análisis comparado en clave axiológico-procedimental

\section{(Teodoro) Yan Guzman Hernández}

Profesor Titular de Derecho Constitucional y Teoría del Derecho de la Facultad de Derecho de la Universidad de La Habana (La Habana, Cuba)

- Juiz constitucional e diálogo jurisdicional multinível: a experiência chilena

\section{Gonzalo Aguilar Cavallo}

Professor de Direito, Diretor do Mestrado em Direito Constitucional e Sub-Diretor do Centro de Estudios Constitucionales de Chile na Universidade de Talca (Santiago, Chile)

- Estado, democracia e corrupção: equações complexas

\section{Rogério Gesta Leal}

Professor Titular da Universidade de Santa Cruz do Sul - UNISC (Santa Cruz do Sul-RS, Brasil)

- Sobre a noção de bem comum no pensamento político ocidental: entre becos e encruzilhadas da dimensão ancestral do moderno conceito de interesse público

\section{José Sergio da Silva Cristóvam}

Professor Adjunto de Direito Administrativo no Curso de Graduação em Direito e no Programa de Mestrado em Direito do PPGD/UFSC (Florianópolis-SC, Brasil)

- A vitória pírrica da democracia constitucional

\section{Fausto Santos de Morais}


Docente da Escola de Direito e Programa de Pós-Graduação Estrito Senso - Mestrado em Direito, Faculdade Meridional - IMED (Passo Fundo-RS, Brasil)

\section{Fernando Gabriel Ghiggi}

Pós-Graduado em Direito Constitucional pela Faculdade de Direito Prof. Damásio de Jesus FDDJ (São Paulo-SP, Brasil)

- Os paradoxos da deliberação judicial colegiada

\section{Guilherme da Franca Couto Fernandes de Almeida}

Doutorando e Mestre em Teoria do Estado e Direito Constitucional pela Pontifícia Universidade Católica do Rio de Janeiro (Rio de Janeiro-RJ, Brasil)

\section{Pedro Henrique Veiga Chrismann}

Professor adjunto da Faculdade de Ciências Sociais Aplicadas Ibmec (Rio de Janeiro-RJ, Brasil)

- A nova cláusula de barreira e a sobrevivência das minorias

\section{Raimundo Augusto Fernandes Neto}

Doutorando em Direito Constitucional pela Universidade de Fortaleza (Fortaleza-CE, Brasil).

\section{Jânio Pereira da Cunha}

Professor do Programa de Pós-Graduação em Direito (Mestrado) do Centro Universitário Christus - UNICHRISTUS (Fortaleza-CE, Brasil).

Seguimos na expectativa de, cada vez mais, ampliar o alcance da difusão dos resultados de pesquisas relevantes na área do Direito Constitucional.

Curitiba, janeiro de 2019.

Prof. Dr. Daniel Wunder Hachem

Editor-Chefe da Revista de Investigações Constitucionais

Prof. Msc. Luzardo Faria

Editor-Adjunto da Revista de Investigações Constitucionais 